\title{
Article
}

\section{Characterization of MnAPO-5 for Ethane Oxydehydrogenation}

Juinn-Yao Wu, Shu-Hua Chien, and Ben-Zu Wan

Ind. Eng. Chem. Res., 2001, 40 (1), 94-100 • DOI: 10.1021/ie000291k

Downloaded from http://pubs.acs.org on November 26, 2008

\section{More About This Article}

Additional resources and features associated with this article are available within the HTML version:

- $\quad$ Supporting Information

- $\quad$ Links to the 1 articles that cite this article, as of the time of this article download

- $\quad$ Access to high resolution figures

- $\quad$ Links to articles and content related to this article

- $\quad$ Copyright permission to reproduce figures and/or text from this article

\section{View the Full Text HTML}

\section{ACS Publications}




\title{
Characterization of MnAPO-5 for Ethane Oxydehydrogenation
}

\author{
J uinn-Yao Wu, '† Shu-Hua Chien, ${ }^{\ddagger}$ and Ben-Zu Wan*,† \\ Department of Chemical Engineering, National Taiwan University, Taipe, Taiwan, Republic of China, and \\ Institute of Chemistry, Academia Sinica, Taipei, Taiwan, Republic of China
}

\begin{abstract}
Manganese-substituted $\mathrm{AlPO}_{4}-5$ molecular sieve (MnAPO-5) was characterized by temperatureprogrammed reduction (TPR) and diffuse reflectance UV-Vis and electron paramagnetic resonance (EPR) spectroscopies, and the results were compared with those of manganese oxides impregnated on $\mathrm{AlPO}_{4}-5\left(\mathrm{Mn} / \mathrm{AlPO}_{4}-5\right)$. It was found from TPR that the manganese interacted strongly with the aluminophosphate surface in MnAPO-5. Higher temperatures were required to reduce the manganese species on MnAPO- 5 by hydrogen than to reduce those on Mn/AIPO ${ }_{4}^{-}$ 5. The TPR, UV-Vis, and EPR results indicate that $\mathrm{Mn}^{2+}$ or $\mathrm{Mn}^{3+}$ was the major oxidation state of manganese in MnAPO-5, in which a small amount of $\mathrm{MnO}_{2}$ or $\mathrm{Mn}_{2} \mathrm{O}_{3}$ was also found. $\mathrm{O}_{2}{ }^{-}$was observed from $\mathrm{AlPO}_{4}-5, \mathrm{MnAPO}-5$, and $\mathrm{Mn} / \mathrm{AIPO}_{4}-5$ by EPR at $\mathrm{g}_{\mathrm{zz}}=2.021, \mathrm{~g}_{\mathrm{xx}}=2.008$, and $g_{y y}=2.003$; it existed on the surface of the aluminophosphate rather than being associated with manganese on either $\mathrm{MnAPO}-5$ or $\mathrm{Mn} / \mathrm{AlPO}_{4}-5$. A kinetic model involving oxygen and ethane adsorption was proposed for ethane oxydehydrogenation over MnAPO-5. The surface reaction was the rate-determining step. The activation energy for the reaction and the enthal py and entropy changes for the adsorptions of ethane and oxygen were obtained in this study. Because positive entropy and enthal py changes for oxygen chemisorption on the MnAPO-5 surface were found, it is proposed that surface rearrangement around the $\mathrm{Mn}$ catalytic center occurred during oxygen chemisorption.
\end{abstract}

\section{Introduction}

$\mathrm{AlPO}_{4}-5$ is a member of the aluminophosphate molecular sieve family, which was discovered by researchers at Union Carbide. ${ }^{1}$ The drawback of the aluminophosphate molecular sieves in applications to catalysis is their neutral framework and low catalytic activities. A great effort has been made to substitute hetero elements for the aluminum or phosphorus in the framework. Recently, thorough reviews on the research progress and the applications of the metal-substituted materials were reported by Weckhuysen et al. and Hartmann and Kevan.2,3 Silicoal uminophosphate, which has silicon substituted for phosphorus in the framework, was found to have Brönsted acidic sites. ${ }^{4,5}$ On the other hand, both Brönsted and Lewis acidic sites of different strengths were observed on transition-metal-substituted AIPO $4-5 .{ }^{6}$ These metal-substituted materials were found to be catalytically active in xylene isomerization, ${ }^{7-9}$ methanol conversion, ${ }^{10,11}$ ethanol dehydration, ${ }^{12}$ propanol dehydration, and propene oligomerization. ${ }^{13}$ Moreover, redox catalytic activities were observed on $\mathrm{AlPO}_{4}-5$ substituted with manganese, ${ }^{14}$ vanadium, ${ }^{15-21}$ cobalt, 22,23 and chromium ${ }^{24}$ in reactions such as ethane or propane oxydehydrogenation and cyclohexane oxidation to cyclohexanone and adipic acid.

MnAPO-5 was reported to be an effective catalyst for ethane oxydehydrogenation to produce ethylene. ${ }^{14}$ The selectivity of ethylene over this catalyst was much higher than those over manganese oxides and manganese phosphates impregnated on $\mathrm{AlPO}_{4}-5$ or over manganese-ion-exchanged SAPO-5. However, the status of manganese in MnAPO-5 for ethane oxydehydrogenation and the reaction mechanism are not clear. Therefore,

* Author to whom correspondence should be addressed. Fax: (+886)-2-23623040. E-mail: benzuwan@ccms.ntu.edu.tw. the aims of this study are to characterize manganese and surface oxygen on MnAPO-5 with experimental techniques of TPR and diffuse reflectance UV-Vis and EPR spectroscopies and to apply the reaction kinetics to an understanding of the mechanism of ethane oxydehydrogenation on MnAPO-5.

\section{Experimental Section}

Catalyst Preparation. $\mathrm{AlPO}_{4}-5$ and $\mathrm{MnAPO}-5$ were synthesized according to the hydrothermal crystallization method reported in our previous papers. ${ }^{12,14}$ The samples were calcined at $823 \mathrm{~K}(2 \mathrm{~K} / \mathrm{min}$ increment from room temperature) under air for $6 \mathrm{~h}$ to remove the templates. The impregnated sample $\mathrm{Mn} / \mathrm{AlPO}_{4}-5$ was prepared by the incipient wetness method with manganese nitrate solution and calcined $\mathrm{AlPO}_{4}-5$. The sample was dried at room temperature and calcined again at $823 \mathrm{~K}$.

Catalyst Characterization. The manganese content in each sample was determined by analyzing the HF dissolved solution with an atomic absorption unit (GBC 906). The X-ray powder diffraction (XRD) patterns were taken with a MAC Science Diffractometer MXP-3 with $\mathrm{Cu} \mathrm{K} \alpha$ radiation. A Hitachi $\mathrm{U} 3410$ unit was used for the diffuse reflectance UV-Vis measurements. A Bruker ER 200D system operating at the X-band was used for the EPR measurements, for which all of the spectra were taken at $77 \mathrm{~K}$ and DPPH was used as a reference. The BET surface area was measured with a Micromeritic Accusorb 2100D unit.

For TPR (temperature-programmed reduction) studies, the catalysts were pretreated at $473 \mathrm{~K}$ under a 25 $\mathrm{mL} / \mathrm{min}$ argon flow for $4 \mathrm{~h}$. The measurements were carried out under a $30 \mathrm{~mL} / \mathrm{min}$ flow $\left(\mathrm{H}_{2} / \mathrm{N}_{2}=1 / 9\right)$ from room temperature to $1073 \mathrm{~K}$. The temperature was monitored with a K-type thermocouple in a quartz 
thermowell located at the center of the catalyst bed. The reduction process was monitored by a thermal conductivity detector (TCD).

Catalytic Reaction and Kinetics Studies. Ethane oxydehydrogenation was carried out in a fixed bed differential type reactor, in which the void space before the catalyst bed was filled with quartz glass wool to prevent free radical side reactions. Catalyst powder (about $200 \mathrm{mg}$ ) was packed into a short section of a 9-mm-o.d. quartz tube. A K-type thermocouple in a quartz thermowell was fixed at the center of the catalyst bed to monitor the reaction temperature. The flow rates of ethane, air, and nitrogen were controlled and read by mass controllers and meters (Brooks 5850 and 5878). In the reaction kinetic measurements, the total volumetric flow rates were maintained at $50 \mathrm{~mL} / \mathrm{min}$, and the contact time for the reaction was at $4.0 \mathrm{mg} \mathrm{min} /$ $\mathrm{mL}$. The partial pressure of ethane was changed within the range $0.1-0.5 \mathrm{~atm}$, and that of oxygen was changed within the range $0.01-0.1 \mathrm{~atm}$. The hydrocarbons and carbon dioxide products were analyzed by an online gas chromatograph (GC) (China Chromatography, 8700T) with a 6 -ft Porapak S column (1/8-in. o.d., SS). Carbon monoxide and oxygen were separated by another GC (Shimadzu, GC-14A) with a 6-ft molecular sieve column $(1 / 8$-in. o.d., SS). Both GC detectors were TCD, and hydrogen was the carrier gas.

\section{Results and Discussion}

Metal Loading, BET Surface Area, and XRD Patterns. As in our previous research results, ${ }^{14}$ the samples of MnAPO-5 and Mn/AIPO ${ }_{4}-5$ showed the same X-ray diffraction patterns as $\mathrm{AlPO}_{4}-5$. No patterns corresponding to mangnese oxide crystals were observed. The manganese loading in MnAPO-5 is $1.1 \mathrm{wt}$ $\%$, and that in $\mathrm{Mn} / \mathrm{AlPO}_{4}-5$ is $0.5 \mathrm{wt} \%$. The BET surface areas of MnAPO-5, AlPO ${ }_{4}-5$, and $\mathrm{Mn} / \mathrm{AlPO}_{4}-5$ are 285, 248 and $140 \mathrm{~m}^{2} / \mathrm{g}$, respectively. Apparently, the lower surface area of $\mathrm{Mn} / \mathrm{AlPO}_{4}-5$ in comparison to that of AIPO ${ }_{4}-5$ was due to the blockage of the $\mathrm{AIPO}_{4}-5$ channels by manganese oxide particles impregnated on the surface.

Characterization by EPR. Figure 1 shows the EPR spectra of $\mathrm{Mn}$-containing AlPO${ }_{4}-5$ samples. It depicts that the calcined MnAPO-5 after evacuation under $10^{-4}$ Torr at room temperature exhibited hyperfine structure similar to that of $\mathrm{Mn} / \mathrm{AlPO}_{4}-5$ with splitting characteristics of octahedral $\mathrm{Mn}^{2+}$. The results confirm the existence of octahedral $\mathrm{Mn}^{2+}$ in both samples. The octahedral $\mathrm{Mn}^{2+}$ in MnAPO-5 may be located either on the defect sites bonded with the framework or on the aluminophosphate surface, such as those in the impregnated samples. The sextet hyperfine structure was centered at $\mathrm{g}=2.002$ with the hyperfine splitting constant $A=95 \mathrm{G}$, which are similar to the values reported by Goldfarb ${ }^{25}$ and Levi et al., ${ }^{26}$ and close to those reported for calcined M nSAPO-11,27 M nAPO-11, and $\mathrm{Mn}$-impregnated $\mathrm{AlPO}_{4}-11,{ }^{28} \mathrm{MnSAPO}-34$, and MnSAPO-44. ${ }^{29}$ After dehydration of the samples at 773 $K$ in vacuum for $3 \mathrm{~h}$, the hyperfine structures coal esced and the splitting constant shrank to $89 \mathrm{G}$ for the MnAPO-5 sample, while the hyperfine splittings disappeared completely for $\mathrm{Mn} / \mathrm{AlPO}_{4}-5$. Based on the work of MAS NMR and EPR spectroscopies and electron spin-echo modulation presented by Goldfarb ${ }^{25}$ and Levi et al., ${ }^{26}$ we believe that, during high-temperature dehydration, the octahedral $\mathrm{Mn}^{2+}$ on the extraframework

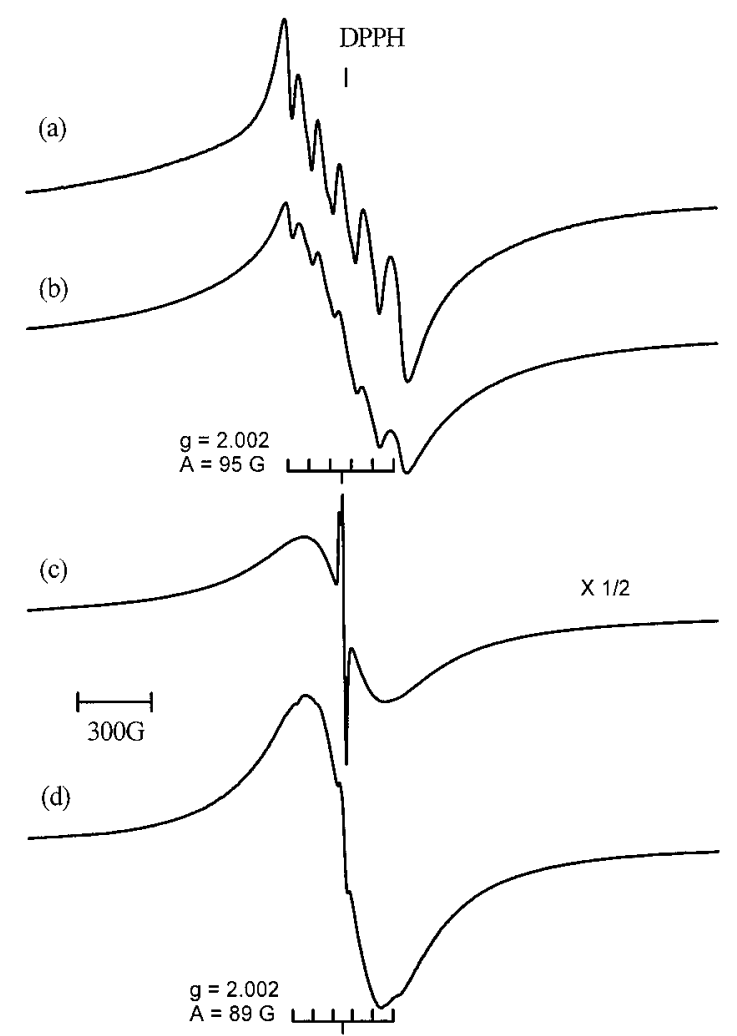

Figure 1. EPR spectra of $\mathrm{Mn}^{2+}$ at $77 \mathrm{~K}$ over calcined (a) $\mathrm{Mn}$ / AlPO 4 -5 after evacuation at room temperature, (b) MnAPO-5 after evacuation at room temperature, (c)Mn/AIPO $4-5$ after evacuation at $773 \mathrm{~K}$, and (d) MnAPO-5-31-5 after evacuation at $773 \mathrm{~K}$.

sites of MnAPO-5 probably migrated irreversibly toward the manganese sites substituted within the framework of aluminophosphate. The increase in the spin-exchange interaction caused the coal escence and reduction of the hyperfine splitting. On the other hand, the EPR spectrum of $\mathrm{Mn} / \mathrm{AlPO}_{4}-5$ after high-temperature dehydration showed that the hyperfine splittings disappeared and that only a broad signal remained. These results demonstrate that the mobility of manganese on the surface of the impregnated sample was even higher, which led to $\mathrm{Mn}^{2+}$ on $\mathrm{Mn} / \mathrm{AlPO}_{4}-5$ being closer to each other (or even aggregated on the AIPO ${ }_{4}-5$ surface) under high-temperature treatment.

No EPR signals with $g$ values between 4 and 6 were observed in our samples. The $\mathrm{g}$ value of 4.27 was assigned to $\mathrm{Mn}^{2+}$ on the distorted tetrahedral framework sites of MnAPO-11 by Sinha et al. ${ }^{30}$ The tetrahedral $\mathrm{Mn}^{2+}$ in framework MnAPO-5 can be excluded in our case. Moreover, as for the manganese oxides impregnated on $\mathrm{Al}_{2} \mathrm{O}_{3}$ reported by $\mathrm{Kijlstra}$ et al., 31 the EPR signals due to $\mathrm{Mn}^{4+}$ were superimposed by those of $\mathrm{Mn}^{2+}$, and cannot be clearly assigned in the present study.

The EPR spectra of $\mathrm{O}_{2}^{-}$species were observed, as shown in Figure 2, at $g_{z z}=2.021, g_{x x}=2.008$, and $\mathrm{g}_{\mathrm{yy}}=2.003$ over $\mathrm{AlPO}_{4}-5, \mathrm{MnAPO}-5$, and $\mathrm{Mn} / \mathrm{AlPO}_{4}-5$ after the samples were evacuated under a $10^{-5}$ Torr vacuum at $773 \mathrm{~K}$ for $3 \mathrm{~h}$. The generation of $\mathrm{O}_{2}{ }^{-}$species might be due to the reduction of oxygen adsorbates on the defect sites of aluminophosphate, which served as effective electron donors after dehydroxylation of $\mathrm{AIPO}_{4}$ molecular si eves. ${ }^{32,33}$ Oxygen might be from the leakage of the EPR cell after degassing. The $g_{z z}$ value can reflect the magnitude of the local crystal field at the oxygen adsorption site. ${ }^{34}$ In the present study, the $g_{z z}$ value of 


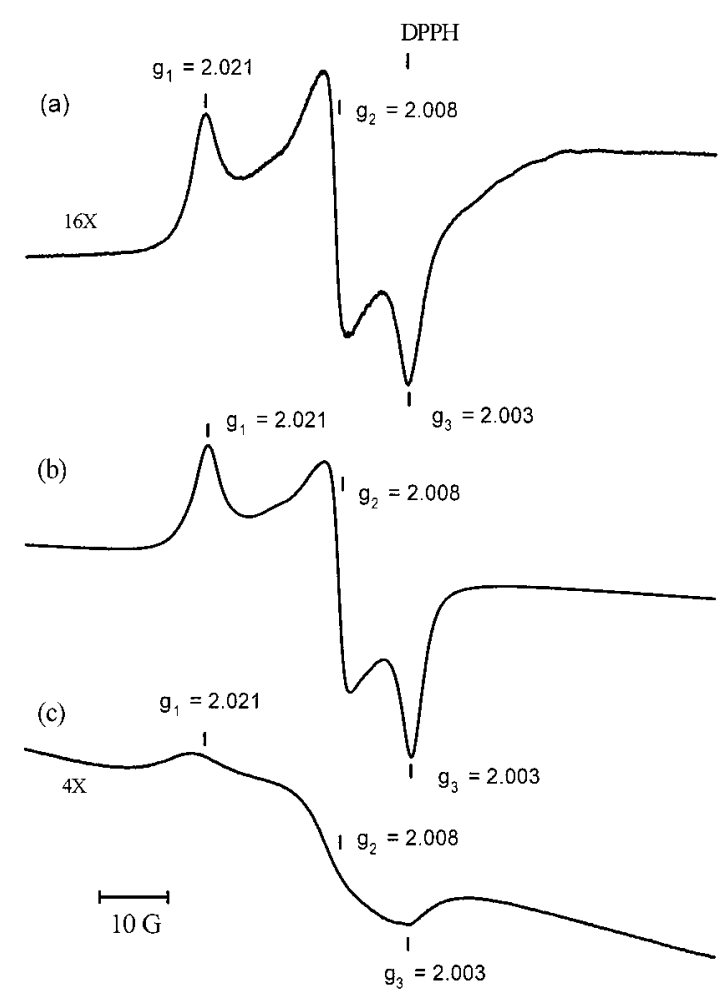

Figure 2. EPR spectra of $\mathrm{O}_{2}^{-}$at $77 \mathrm{~K}$ over calcined (a) $\mathrm{AlPO}_{4}-5$, (b) $\mathrm{Mn} / \mathrm{AlPO}_{4}-5$, and (c) MnAPO-5 after evacuation at $773 \mathrm{~K}$ for 3 h.

2.021 is too great for $\mathrm{Al}^{3+}, \mathrm{Mn}^{2+}$, or $\mathrm{Mn}^{3+}(+2$ and +3 oxidation states of metal ions); moreover, even there is $\mathrm{O}_{2}^{-}$on $\mathrm{Mn}^{2+}$ or $\mathrm{Mn}^{3+}$, it can not be observed by EPR because of the paramagnetic property of manganese species. These results suggest that $\mathrm{O}_{2}^{-}$detected by EPR during this research was located at $\mathrm{P}^{5+}$ sites in aluminophosphate. ${ }^{34}$ Consequently, the same $g$ values were observed for all of the samples, as shown in Figure 2. On the other hand, the same $g$ values provide a further evidence that the observed $\mathrm{O}_{2}{ }^{-}$species from the EPR spectra were on the aluminophosphate surface rather than on manganese sites; otherwise, different $g$ values from those on $\mathrm{AlPO}_{4}-5$ should have been observed on MnAPO-5 and $\mathrm{Mn} / \mathrm{AlPO}_{4}-5$. Furthermore, the similar $\mathrm{O}_{2}{ }^{-}$intensities observed on $\mathrm{Mn} / \mathrm{AlPO}_{4}-5$ and $\mathrm{AlPO}_{4}-5$ suggest that the surface properties of $\mathrm{AIPO}_{4}-5$ are not interfered with significantly by the impregnation of manganese oxides. This may be due to the manganese oxides aggregating to form nanosize particles (not observed by XRD) on $\mathrm{AlPO}_{4}-5$ after high-temperature treatment. Nevertheless, because of the substitution of manganese in the framework which either caused the decrease in aluminophosphate units or caused the dipolar interaction between $\mathrm{Mn}$ and $\mathrm{O}_{2}^{-}, \mathrm{MnAPO}-5$ presented less $\mathrm{O}_{2}{ }^{-}$EPR intensity and a broader spectrum than $\mathrm{AlPO}_{4}-5$.

Characterization by TPR. The TPR results, shown in Figure 3, reveal that manganese oxides impregnated on $\mathrm{AlPO}_{4}-5$ (sample $\mathrm{Mn} / \mathrm{AlPO}_{4}-5$ ) can be reduced at around 573 and $673 \mathrm{~K}$, values that are close to the temperatures for the reduction of manganese oxides (i.e., the majority were $\mathrm{MnO}_{2}$ and some were $\mathrm{Mn}_{2} \mathrm{O}_{3}$ ) to $\mathrm{MnO}$ supported on $\mathrm{Al}_{2} \mathrm{O}_{3}$, while the impregnated manganese nitrate was the precursor. ${ }^{35,36} \mathrm{~F}$ or calcined MnAPO-5, a small TPR band at around $573 \mathrm{~K}$ and a broad band from 643 to $1073 \mathrm{~K}$ with a shoulder cl ose to $673 \mathrm{~K}$ were observed. These results suggest that a small

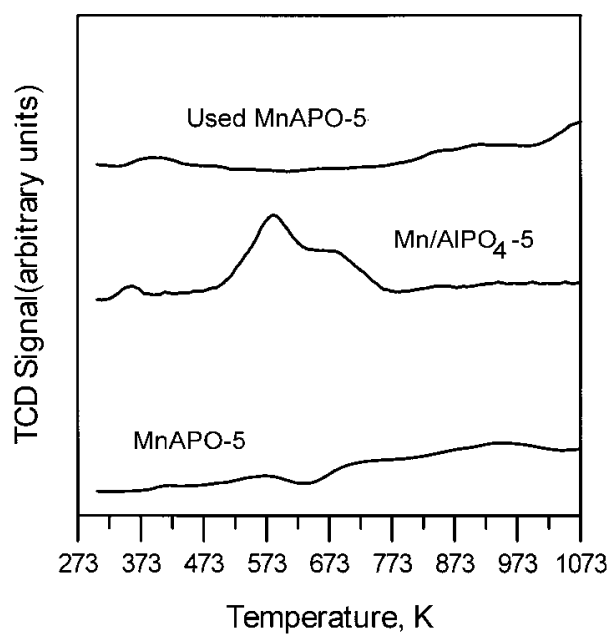

Figure 3. Temperature-programmed reduction of calcined MnAPO5, $\mathrm{Mn} / \mathrm{AlPO}_{4}-5$ and used M nAPO-5 after ethane oxydehydrogenation reaction.

number of manganese ions in MnAPO-5 were loosely located in the form of impregnated $\mathrm{MnO}_{2}$ or $\mathrm{Mn}_{2} \mathrm{O}_{3}$ on the surface of aluminophosphate, while the rest were bonded strongly with the framework. Therefore, the TPR results are consistent with the EPR spectra and demonstrate that most of the manganese in MnAPO-5 was bonded with the framework. The bonding causes manganese in MnAPO- 5 to be less mobile and more difficult to be reduced. Furthermore, after the ethane oxydehydrogenation reaction at $773 \mathrm{~K}$, the used and still active M nAPO- 5 catalysts showed only weak TPR bands at temperatures higher than $773 \mathrm{~K}$, as well as a band starting to grow at around $1000 \mathrm{~K}$, which was, however, above the limit of our detection. These results suggest that the extraframework manganese oxides along with manganese on the defect sites were reduced to $\mathrm{Mn}^{2+}$ and that the interaction between the manganese and the framework of MnAPO-5 was strengthened after the catalytic reaction. In the study by Parrillo et al., ${ }^{13}$ it was presented that significant defects exist in MnAPO-5 following calcination and that these defects can be removed by exposure to reactive molecules (i.e., isopropylamine, propene, or 2-propanol in their study). In this study, ethane and ethylene were present in the reaction system. They were the reactive molecules either for reducing manganese compounds to $\mathrm{Mn}^{2+}$ species or for decreasing the number of defect sites on MnAPO-5. Therefore, in the present study, the TPR bands between 673 and $1000 \mathrm{~K}$ were assigned to the reduction of manganese on the surface defect sites, and those above $1000 \mathrm{~K}$ were assigned to the reduction of manganese located in the tetrahedral framework. After the catalytic reactions, the TPR bands corresponding to the reduction of manganese on the defect sites decreased significantly, and the bands corresponding to the reduction of manganese in the tetrahedra framework seemed to remain.

Characterization by Diffuse Reflectance UVVis Spectroscopy. The diffuse reflectance UV-Vis spectra of calcined MnAPO-5, Mn/AIPO ${ }_{4}-5$, and the samples used in ethane oxydehydrogenation reaction are shown in Figure 4. The lower band intensities for $\mathrm{Mn} / \mathrm{AlPO}_{4}-5$ were attributed to the lower manganese loading in this sample. Both samples exhibited two strong and unresolved charge-transfer bands at about 220 and $258 \mathrm{~nm}$ in UV region. For fresh and used MnAPO-5, the band at $220 \mathrm{~nm}$ was more intense than 


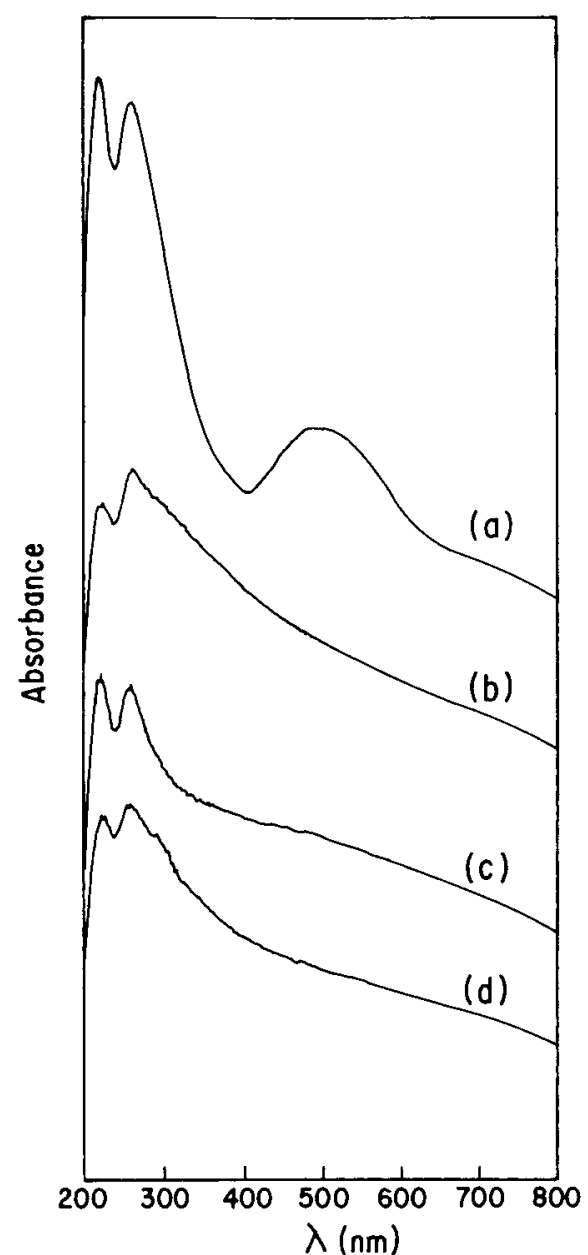

Figure 4. Diffuse reflectance $U V-V$ is spectra of calcined (a) MnAPO-5, (b) Mn/AIPO $4-5$; (c) used MnAPO-5, and (d) used Mn/ $\mathrm{AlPO}_{4}-5$ after the ethane oxydehydrogenation reaction.

that at $258 \mathrm{~nm}$; in contrast, the rel ative band intensities were reversed for fresh and used $\mathrm{Mn} / \mathrm{AlPO}_{4}-5$. The fresh calcined MnAPO-5 was pink in color and exhibited unique absorption at around $500 \mathrm{~nm}$ in visible region, which may correspond to the ${ }^{5} \mathrm{E}_{\mathrm{g}} \rightarrow{ }^{5} \mathrm{~T}_{2 \mathrm{~g}}$ transition in $\mathrm{Mn}^{3+}$ or the ${ }^{4} \mathrm{~A}_{2} \rightarrow{ }^{4} \mathrm{~T}_{2}$ transition in $\mathrm{Mn}^{4+}$ species. However, because the transitions from $\mathrm{Mn}^{2+}$ species are all spin-forbidden and the absorption intensity around 500 $\mathrm{nm}$ from $\mathrm{Mn}^{2+}$ should be low, the existence of $\mathrm{Mn}^{2+}$ in this calcined sample cannot be excluded. ${ }^{29,31,37 ~ I n ~ f a c t, ~}$ we have observed $\mathrm{Mn}^{2+}$ in both calcined $\mathrm{MnAPO}-5$ and $\mathrm{Mn} / \mathrm{AlPO}_{4}-5$ from EPR spectra. Moreover, the fresh calcined $\mathrm{Mn} / \mathrm{AlPO}_{4}-5$ was gray in color and exhibited broad and strong absorptions in both the UV and the visible regions, which suggests that most of the manganese species were in high oxidation states that are spin-allowed (i.e., $\mathrm{Mn}^{3+}$ or $\mathrm{Mn}^{4+}$ of $\mathrm{Mn}_{2} \mathrm{O}_{3}$ or $\mathrm{MnO}_{2}$ ). The impregnated manganese oxides might be aggregated on the al uminophosphate surface, which would cause broad absorption bands in the UV and visible regions. Nevertheless, after the ethane oxydehydrogenation reaction, the bands of $\mathrm{Mn} / \mathrm{AlPO}_{4}-5$ in the UV-Vis region (higher than $280 \mathrm{~nm}$ ) decreased considerably in intensity, and the absorption band at around $500 \mathrm{~nm}$ from MnAPO-5 nearly disappeared, along with the sample col or changed to gray. The decrease in band intensity of both samples indicates that a significant number of the manganese species were reduced to $\mathrm{Mn}^{2+}$ of weak absorption after the reaction.
In summary of the EPR, TPR, and UV-Vis results, the fresh calcined MnAPO-5 was pink in color and contained $\mathrm{Mn}^{2+}, \mathrm{Mn}^{3+}$, and a small amount of impregnated $\mathrm{Mn}_{2} \mathrm{O}_{3}$ or $\mathrm{MnO}_{2}$. Some of the $\mathrm{Mn}^{2+}$ ions were in octahedral coordination and contributed to the EPR hyperfine structure. Most of the manganese ions were coordinated with either the defect sites or the framework of the al uminophosphate. Therefore, high temperatures were required for the reduction of MnAPO- 5 by hydrogen, and the EPR hyperfine structure was re tained after high-temperature evacuation. The gray $\mathrm{Mn} /$ AlPO $_{4}-5$ contained mainly $\mathrm{Mn}_{2} \mathrm{O}_{3}$ or $\mathrm{MnO}_{2}$ and a small amount of octahedral $\mathrm{Mn}^{2+}$. Because manganese oxides interact with $\mathrm{AlPO}_{4}-5$ weakly, relatively low temperatures (i.e., about $573 \mathrm{~K}$ ) were required for the reduction of $\mathrm{Mn} / \mathrm{AlPO}_{4}-5$ by hydrogen. The EPR hyperfine structure disappeared because of the spin-exchange interaction after high-temperature evacuation.

In our past work, ${ }^{14}$ we demonstrated that the series of reactions of ethane oxydehydrogenation occurred on MnAPO-5; ethane was first partially oxidized to ethylene and water, and some of the ethylene was later totally oxidized to carbon oxides and water. We also demonstrated in the same work that the major products from ethane oxidation on $\mathrm{Mn} / \mathrm{AlPO}_{4}-5$ are carbon oxides and water, which occurred even at low ethane conversions. From the characterization of this work, we can conclude that the species responsible for the total combustion on $\mathrm{Mn} / \mathrm{AlPO}_{4}-5$ are $\mathrm{MnO}_{2}, \mathrm{Mn}_{2} \mathrm{O}_{3}$, or $\mathrm{MnO}$ of manganese oxides impregnated on the surface and that the species for the partial oxidation on MnAPO-5 is the lower-oxidation-state manganese bonded on the defect sites or the framework.

Because MnAPO-5 exhibits the catalytic properties for partial oxidation of ethane to ethyl ene, attempts to elucidate the rate equation and the reaction mechanism of partial oxidation were made in the next part of this work.

Reaction Kinetics of Ethane Oxydehydrogenation Catalyzed by MnAPO-5. The rates of ethane oxydehydrogenation to form ethylene over MnAPO-5 were measured with different concentrations of ethane and oxygen. The reaction temperatures were controlled in the range of 748 to $793 \mathrm{~K}$, and the total pressure was kept at $1 \mathrm{~atm}$. The ethane conversions were maintained to be less than $4 \%$, to fulfill the requirement of a differential reactor. The reaction rates obtained at steady state as a function of reactant partial pressure are listed in Table 1. Several kinetic models and rate equations were developed to fit the rate data. A SAS package was applied to perform the regression. The parameters in each proposed rate equation were estimated from the linear regression. When any of the estimated parameters was negative, that proposed rate equation was eliminated from further consideration. Thus, more than thirty rate equations from different reaction mechanisms (with different rate-determining steps), such as Langmuir-Hinshelwood type with molecular or atomic adsorption on single or dual sites, a Rideal type for adsorption, or several reduction-oxidation mechanisms, have been examined. Only the following equation turned out to fit all of the kinetics data from each temperature satisfactorily:

$$
\mathrm{r}_{\mathrm{C}_{2} \mathrm{H}_{4}}=\frac{\mathrm{C}_{\mathrm{t}}^{2} \mathrm{~K}_{1}^{2} \mathrm{~K}_{2} \mathrm{~K}_{3} \mathrm{P}_{\mathrm{C}_{2} \mathrm{H}_{6}} \mathrm{P}_{\mathrm{O}_{2}}^{2}}{\left(1+\mathrm{K}_{1} \mathrm{P}_{\mathrm{O}_{2}}+\mathrm{K}_{1} \mathrm{~K}_{2} \mathrm{P}_{\left.\mathrm{C}_{2} \mathrm{H}_{6} \mathrm{P}_{\mathrm{O}_{2}}\right)^{2}}\right.}
$$


Table 1. Experimental Data of Ethylene Formation Rates, Reactant Partial Pressures, and Reactant Conversions over MnAPO-5 at Different Temperatures

\begin{tabular}{lllllr}
\hline $\mathrm{T} / \mathrm{K}$ & $\begin{array}{c}\mathrm{r}_{\mathrm{C}_{2} \mathrm{H}_{4}} \\
\left(\mathrm{~mol} \mathrm{~s} \mathrm{~g}^{-1}\right)\end{array}$ & $\begin{array}{c}\mathrm{P}_{\mathrm{O}_{2}} \\
(\mathrm{~atm})\end{array}$ & $\begin{array}{c}\mathrm{P}_{\mathrm{C}_{2} \mathrm{H}_{6}} \\
(\mathrm{~atm})\end{array}$ & $\begin{array}{c}\mathrm{X}_{\mathrm{C}_{2} \mathrm{H}_{6}} \\
\left(\% \mathrm{~m}^{\mathrm{a}}\right)\end{array}$ & $\begin{array}{r}\mathrm{X}_{\mathrm{O}_{2}} \\
\left.(\%)^{b}\right)\end{array}$ \\
\hline 793 & $4.85 \times 10^{-7}$ & 0.0188 & 0.498 & 0.55 & 22.1 \\
& $1.40 \times 10^{-6}$ & 0.0376 & 0.498 & 1.23 & 20.0 \\
& $1.60 \times 10^{-6}$ & 0.0454 & 0.497 & 1.31 & 19.3 \\
& $1.15 \times 10^{-6}$ & 0.0794 & 0.497 & 1.23 & 11.4 \\
& $1.28 \times 10^{-6}$ & 0.100 & 0.497 & 1.27 & 8.8 \\
& $1.20 \times 10^{-6}$ & 0.101 & 0.397 & 1.51 & 7.8 \\
& $6.50 \times 10^{-7}$ & 0.102 & 0.238 & 1.80 & 6.3 \\
& $6.37 \times 10^{-7}$ & 0.102 & 0.198 & 1.91 & 5.5 \\
773 & $4.30 \times 10^{-7}$ & 0.103 & 0.0988 & 2.62 & 3.8 \\
& $2.90 \times 10^{-7}$ & 0.0181 & 0.498 & 0.70 & 28.2 \\
& $4.70 \times 10^{-7}$ & 0.0376 & 0.498 & 1.12 & 21.3 \\
& $5.20 \times 10^{-7}$ & 0.0436 & 0.497 & 1.23 & 27.2 \\
& $6.70 \times 10^{-7}$ & 0.0769 & 0.497 & 1.52 & 18.4 \\
& $8.00 \times 10^{-7}$ & 0.0956 & 0.495 & 1.96 & 18.2 \\
& $6.50 \times 10^{-7}$ & 0.0971 & 0.396 & 2.03 & 15.1 \\
& $5.25 \times 10^{-7}$ & 0.0992 & 0.236 & 2.83 & 11.3 \\
& $4.50 \times 10^{-7}$ & 0.0987 & 0.196 & 3.12 & 11.5 \\
& $3.14 \times 10^{-7}$ & 0.101 & 0.0979 & 4.10 & 7.2 \\
& $1.58 \times 10^{-7}$ & 0.0197 & 0.499 & 0.32 & 11.6 \\
& $2.40 \times 10^{-7}$ & 0.0393 & 0.498 & 0.56 & 13.4 \\
& $2.90 \times 10^{-7}$ & 0.0474 & 0.499 & 0.63 & 12.5 \\
& $4.20 \times 10^{-7}$ & 0.0764 & 0.497 & 0.96 & 11.8 \\
& $5.50 \times 10^{-7}$ & 0.0986 & 0.496 & 1.30 & 12.2 \\
& $3.70 \times 10^{-7}$ & 0.0990 & 0.397 & 1.44 & 11.4 \\
& $3.85 \times 10^{-7}$ & 0.0961 & 0.238 & 1.93 & 9.5 \\
& $3.65 \times 10^{-7}$ & 0.0958 & 0.198 & 2.29 & 8.7 \\
& $1.80 \times 10^{-7}$ & 0.0908 & 0.0986 & 2.95 & 6.1
\end{tabular}

${ }^{a} \mathrm{X}_{\mathrm{C}_{2} \mathrm{H}_{6}}$ represents the conversion of $\mathrm{C}_{2} \mathrm{H}_{6} \cdot{ }^{b} \mathrm{X}_{\mathrm{O}_{2}}$ represents the conversion of $\mathrm{O}_{2}$.

where $\mathrm{r}_{2} \mathrm{H}_{4}$ represents the ethylene formation rate, $\mathrm{C}_{t}$ is the total number of active sites on MnAPO-5, and $\mathrm{P}$ is the partial pressure. The rest of the parameters correspond to the rate constants $(\mathrm{k})$ and equilibrium constants $(\mathrm{K})$ of the following mechanism:

$$
\begin{gathered}
\mathrm{O}_{2}+\mathrm{S} \stackrel{\mathrm{K}_{1}}{\longrightarrow} \mathrm{S}_{1} \\
\mathrm{C}_{2} \mathrm{H}_{6}+\mathrm{S}_{1} \stackrel{\mathrm{K}_{2}}{\longrightarrow} \mathrm{C}_{2} \mathrm{H}_{6} \mathrm{~S}_{1} \\
\mathrm{C}_{2} \mathrm{H}_{6} \mathrm{~S}_{1}+\mathrm{S}_{1} \stackrel{\mathrm{k}_{3}}{\longrightarrow} \mathrm{C}_{2} \mathrm{H}_{4} \mathrm{~S}_{1}+\mathrm{H}_{2} \mathrm{~S}_{1} \\
\mathrm{H}_{2} \mathrm{~S}_{1} \stackrel{\mathrm{K}_{4}}{\leftrightarrow} \mathrm{H}_{2} \mathrm{O}+\mathrm{S}_{1}^{\prime} \\
\mathrm{C}_{2} \mathrm{H}_{6}+\mathrm{S}_{1} \stackrel{\mathrm{K}_{5}}{\longleftrightarrow} \mathrm{C}_{2} \mathrm{H}_{4}+\mathrm{H}_{2} \mathrm{O}+\mathrm{S} \\
\mathrm{C}_{2} \mathrm{H}_{4} \mathrm{~S}_{1} \stackrel{\mathrm{K}_{6}}{\longleftrightarrow} \mathrm{C}_{2} \mathrm{H}_{4}+\mathrm{S}_{1}
\end{gathered}
$$

where $S$ is an active site on MnAPO- $5, S_{1}$ is a site containing an oxygen molecule, and $\mathrm{S}_{1}{ }^{\prime}$ is a site containing an oxygen atom. Because of the low reaction conversions maintained during the kinetic measurements, the product concentrations (i.e., $\mathrm{C}_{2} \mathrm{H}_{4}$ and $\mathrm{H}_{2} \mathrm{O}$ ) were assumed to be low and can be neglected in the rate equation. The ratedetermining step is the surface reaction shown in eq 4 . The rest of the reaction steps were assumed to be fast and at equilibrium, especially reaction 6 , in which $S_{1}{ }^{\prime}$ appears, which is very active for partial oxidation. It can be assumed that $\mathrm{S}_{1}{ }^{\prime}$ was very short-lived and is from the oxide surface containing $\mathrm{O}^{-}$. $\mathrm{O}^{-}$cannot be detected by EPR spectroscopy in this study because of the paramagnetic nature of manganese species.

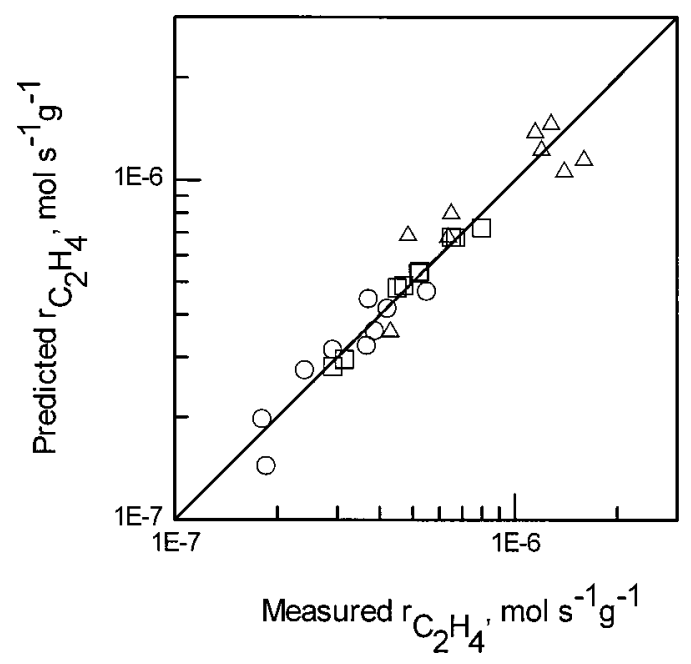

Figure 5. Comparison of predicted and measured ethylene production rates over MnAPO-5 at $748 \mathrm{~K}(\mathrm{O}), 773 \mathrm{~K}(\square)$, and 793 $\mathrm{K}(\triangle)$.

Table 2. Rate Constants and Equilibrium Constants for Surface Reaction and Adsorptions over MnAPO-5 at Different Reaction Temperatures

\begin{tabular}{cccc}
\hline $\begin{array}{c}\mathrm{T} \\
(\mathrm{K})\end{array}$ & $\begin{array}{c}\mathrm{C}_{\mathrm{t}}^{2} \mathrm{~K}_{3} \\
\left(\mathrm{~mol} \mathrm{~g}^{-1} \mathrm{~s}^{-1 \mathrm{a}}\right)\end{array}$ & $\begin{array}{c}\mathrm{K}_{1} \\
\left(\mathrm{~atm}^{-1} \mathrm{~b}\right)\end{array}$ & $\begin{array}{c}\mathrm{K}_{2} \\
\left(\mathrm{~atm}^{-1 \mathrm{c}}\right)\end{array}$ \\
\hline 793 & $1.61 \times 10^{-5}$ & 72.73 & 0.31 \\
773 & $4.00 \times 10^{-6}$ & 36.26 & 1.53 \\
748 & $2.96 \times 10^{-6}$ & 19.25 & 2.16
\end{tabular}

${ }^{a} \mathrm{k}_{3}$ represents the rate constant of the surface reaction of adsorbed $\mathrm{C}_{2} \mathrm{H}_{6}$ to produce adsorbed $\mathrm{C}_{2} \mathrm{H}_{4}$ and $\mathrm{H}_{2}$. ${ }^{\text {b }} \mathrm{K}_{1}$ represents the adsorption equilibrium constant of oxygen molecules on MnAPO-5. ' ${ }^{c} K_{2}$ represents the adsorption equilibrium constant of ethane on MnAPO-5 on which oxygen has been adsorbed.

Figure 5 shows that the rate data from experiments at different temperatures were in good agreement with those estimated from the rate of eq 1 developed from this research. The mean error was about $14 \%$. The random distribution around the diagonal line of empirical and calculated rate values suggests that this rate equation describes all of the experimental results quite well. The values of $C_{t}^{2} K_{3}, K_{1}$, and $K_{2}$ at different reaction temperatures obtained from the linear regression are listed in Table 2, where $\mathrm{k}_{3}$ is the rate constant for the rate-determining step in eq 4 and $K_{1}$ and $K_{2}$ are the equilibrium constants for the adsorptions and reactions in eqs 2 and 3 . The reaction parameters can be expressed as a function of temperature through the equations

$$
\begin{gathered}
\mathrm{C}_{\mathrm{t}}^{2} \mathrm{~K}_{3}=\mathrm{A} \exp \left(-\mathrm{E}_{\mathrm{d}} / \mathrm{RT}\right) \\
\mathrm{K}_{1}=\exp \left(\Delta \mathrm{S}_{1} / \mathrm{R}\right) \exp \left(-\Delta \mathrm{H}_{1} / \mathrm{RT}\right) \\
\mathrm{K}_{2}=\exp \left(\Delta \mathrm{S}_{2} / \mathrm{R}\right) \exp \left(-\Delta \mathrm{H}_{2} / \mathrm{RT}\right)
\end{gathered}
$$

where $E_{a}$ is the activation energy and $A$ is the Arrhenius constant for the surface reaction of the rate-determining step. $\Delta \mathrm{H}_{1}$ and $\Delta \mathrm{H}_{2}$ are the enthalpy changes for the chemisorption of oxygen on MnAPO-5 to produce $S_{1}$ and for the reaction of ethane with $S_{1}$, respectively. $\Delta S_{1}$ and $\Delta \mathrm{S}_{2}$ are the entropy changes for the related processes. From Figure 6, the parameters in eqs 8-10 were estimated and are listed in Table 3. The linear correlation factors, $\gamma$, of the three lines are 0.91, 0.99 and 0.91, respectively, which reflects acceptable linear relations 


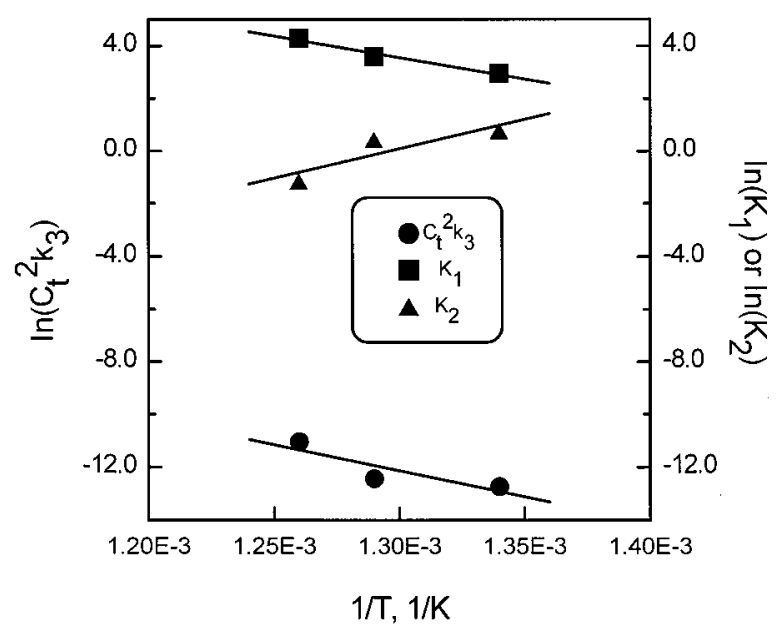

Figure 6. Arrhenius plots of the product of the square of the total number of active sites and the ethane oxydehydrogenation surface reaction rate constant $\left(\mathrm{C}_{\mathrm{t}}{ }^{2} \mathrm{k}_{3}\right)$, the oxygen adsorption equilibrium constant $\left(\mathrm{K}_{1}\right)$, the and ethane adsorption equilibrium constant $\left(\mathrm{K}_{2}\right)$ over MnAPO-5.

Table 3. Entropy and Enthalpy Changes for the Adsorptions of Oxygen and Ethane and Activation Energy for the Surface Reaction over MnAPO-5

\begin{tabular}{clcc}
\hline$\gamma^{\mathrm{a}}$ & \multicolumn{1}{c}{$\Delta \mathrm{S}$} & $\begin{array}{c}\Delta \mathrm{H} \\
\left(\mathrm{kJ} \mathrm{mol} \mathrm{mol}^{-1} \mathrm{c}\right)\end{array}$ & $\begin{array}{c}\mathrm{E}_{\mathrm{a}} \\
\left(\mathrm{kJ} \mathrm{mol} \mathrm{mol}^{-1 \mathrm{~d}}\right)\end{array}$ \\
\hline 0.990 & $\Delta \mathrm{S}_{1}=217.6$ & $\Delta \mathrm{H}_{1}=146.4$ & \\
0.906 & $\Delta \mathrm{S}_{2}=-267.8$ & $\Delta \mathrm{H}_{2}=-205$. & \\
0.906 & & & 178.6
\end{tabular}

a Linear correlation factor. ${ }^{b}$ Entropy change for adsorption; $\Delta \mathrm{S}_{1}$ represents that of oxygen, and $\Delta S_{2}$ represents that of ethane. c Enthalpy change for the adsorption; $\Delta \mathrm{H}_{1}$ represents that of oxygen, and $\Delta \mathrm{H}_{2}$ represents that of ethane. ${ }^{\mathrm{d}}$ Activation energy for the surface reaction.

of the three lines $(\gamma=1$ represents a perfect linear relationship). The activation energy of $178.6 \mathrm{~kJ} \mathrm{~mol}-1$ reveals the general catalytic reaction. The negative changes of entropy and enthalpy $\left(-267.8 \mathrm{~J} \mathrm{~mol}^{-1} \mathrm{~K}^{-1}\right.$ and $-205 \mathrm{~kJ} \mathrm{~mol}^{-1}$, respectively) for the reaction in eq 3 indicate that the reaction of ethane with the active center on MnAPO-5 surface is exothermic and causes a decrease in degrees of freedom. In contrast, the positive changes of entropy and enthal py (217.6 $\mathrm{J} \mathrm{mol}^{-1} \mathrm{~K}^{-1}$ and $146.4 \mathrm{~kJ} \mathrm{~mol}^{-1}$, respectively) for oxygen adsorption in eq 2 indicate that oxygen chemisorption on MnAPO-5 is endothermic and results in an increase in degrees of freedom.

The high negative enthal pty change of eq 3 suggests that the reaction of ethane with the active center of MnAPO-5 is not a simple chemisorption process. It might be the combination of chemisorption of ethane and some reaction of ethane on the chemisorption site. Because an exothermic reaction is expected, the adsorbed ethane might have partially reacted with oxygen on the active center of MnAPO-5. On the other hand, the positive changes of enthalpy and entropy might imply the dissociation of oxygen molecules during their chemisorption on MnAPO-5 surface in eq 2. However, we cannot detect $\mathrm{O}^{-}$on MnAPO-5 by EPR spectroscopy in this study because of paramagnetic property of the manganese species. ${ }^{38}$ In addition, the rate equation derived from the mechanism with complete oxygen dissociation cannot fit the reaction kinetic data successfully. It is noticeable that the $\mathrm{Al}-\mathrm{O}$ and $\mathrm{P}-\mathrm{O}$ bonds in aluminophosphate are not as covalent as the $\mathrm{Si}-\mathrm{O}$ bonds in $\mathrm{SiO}_{2}$; the framework of the aluminophosphates is more hydrophilic and flexible than that of zeolites. Therefore, the increase in entropy and enthal py for the chemisorption of oxygen might be attributable to the rearrangement of the coordination environment around $\mathrm{Mn}$ centers. I ndeed, it was observed in the experiments of ethane oxydehydrogenation on MnAPO-5 catalysts that an induction period of about 100 min was al ways required to reach a new steady state from previous steady state when changes of reactant concentrations were made in the reactor; similar phenomena were not obvious for the same reaction on either $\mathrm{Mn} / \mathrm{AlPO}_{4}-5$ or $\mathrm{AlPO}_{4}-5 .{ }^{39}$ The required induction period might provide some evidence for the rearrangement of coordination environment around $\mathrm{Mn}$ in MnAPO-5.

Although $\mathrm{O}_{2}{ }^{-}$was observed on the MnAPO-5 surface from EPR studies, it is believed that the observed $\mathrm{O}_{2}^{-}$ is present on $\mathrm{P}^{5+}$ sites rather than on manganese in $\mathrm{MnAPO}-5$. Since the surface of $\mathrm{AlPO}_{4}-5$ provided very Iow catalytic activity for partial or total oxidation of ethane, ${ }^{39}$ the observed $\mathrm{O}_{2}{ }^{-}$on MnAPO-5 was not considered to be the major active oxygen species for ethane oxydehydrogenation.

\section{Conclusions}

From the results of TPR, diffuse reflectance UV-Vis, and EPR studies, it can be concluded that the different catalytic properties of manganese-substituted AIPO $4-5$ (MnAPO-5) and manganese-oxide-impregnated $\mathrm{AlPO}_{4}-5$ $\left(\mathrm{Mn} / \mathrm{AlPO}_{4}-5\right)$ for ethane oxidation are due to the presence of different manganese species. The primary manganese species on MnAPO-5 were $\mathrm{Mn}^{2+}$ or $\mathrm{Mn}^{3+}$, which presented as the defect sites and bonded strongly with the framework of aluminophosphate. On the other hand, those on $\mathrm{Mn} / \mathrm{AlPO}_{4}-5$ are $\mathrm{Mn}^{3+}$ or $\mathrm{Mn}^{4+}$ in the form of $\mathrm{Mn}_{2} \mathrm{O}_{3}$ and $\mathrm{MnO}_{2}$. EPR data revealed that, although there was some $\mathrm{Mn}^{2+}$ on $\mathrm{Mn} / \mathrm{AlPO}_{4}-5$, the mobility of these ions on the surface was high. Therefore, after dehydration at high temperature, the interaction between manganese caused the disappearance of hyperfine structure. The TPR results demonstrated that a relatively lower temperature was required for the reduction of $\mathrm{Mn} / \mathrm{AlPO}_{4}-5$ by hydrogen than for the reduction by hydrogen of MnAPO-5, indicating the high oxidation capability of $\mathrm{Mn} / \mathrm{AlPO}_{4}-5$ for total oxidation of hydrocarbons to carbon oxides and water.

$\mathrm{O}_{2}^{-}$was detected by EPR spectroscopy on MnAPO-5, $\mathrm{Mn} / \mathrm{AlPO}_{4}-5$, and $\mathrm{AlPO}_{4}-5$. However, the observed $\mathrm{O}_{2}{ }^{-}$ was not the active species for ethane oxydehydrogenation. F rom the positive changes in entropy and enthal py for oxygen chemisorption on MnAPO-5, it is likely that rearrangement of the coordination environment around $\mathrm{Mn}$ center occurred during oxygen chemisorption. The adsorbed $\mathrm{O}_{2}$ mol ecules were not completely dissociated because the fitted rate equation did not reflect the complete dissociation mechanism.

For ethane oxydehydrogenation, the reaction model of a surface reaction as the rate-determining step was proposed. Under the reaction conditions used in this study, the rate equation of ethane oxydehydrogenation over MnAPO-5 can be expressed as

$$
\mathrm{r}_{\mathrm{C}_{2} \mathrm{H}_{4}}=\frac{\mathrm{C}_{\mathrm{t}}^{2} \mathrm{~K}_{1}^{2} \mathrm{~K}_{2} \mathrm{~K}_{3} \mathrm{P}_{\mathrm{C}_{2} \mathrm{H}_{6}} \mathrm{P}_{\mathrm{O}_{2}}^{2}}{\left(1+\mathrm{K}_{1} \mathrm{P}_{\mathrm{O}_{2}}+\mathrm{K}_{1} \mathrm{~K}_{2} \mathrm{P}_{\left.\mathrm{C}_{2} \mathrm{H}_{6} \mathrm{P}_{\mathrm{O}_{2}}\right)^{2}}\right.}
$$




\section{Acknowledgment}

Financial support from National Science Council, Taiwan, R.O.C. is appreciated.

\section{Literature Cited}

(1) Wilson, S. T.; Lok, B. M.; Messina, C. A.; Cannan, T. R.; Flanigen, E. M. Aluminophosphate Molecular Sieves: A N ew Class of Microporous Crystalline Inorganic Solids. J. Am. Chem. Soc. 1982, 104, 1146.

(2) Weckhuysen, B. M.; Rao, R. R.; Martens, J . A.; Schoonheydt, R. A. Transition Metal I ons in Microporous Crystalline Aluminophosphates: I somorphous Substitution. Eur. J . Inorg. Chem. 1999, 565.

(3) Hartmann, M.; Kevan, L. Transition-Metal Ions in Aluminophosphate and Silicoaluminophosphate Molecular Sieves: Location, Interaction with Adsorbates and Catalytic Properties. Chem. Rev. 1999, 99 (3), 639.

(4) Lok, B. M.; Messina, C. A.; Patton, R. L.; Gajek, R. T.; Cannan, T. R.; Flanigen, E. M. Crystalline Metal Aluminophosphates. U.S. Patent 4,440,871, 1984.

(5) Lok, B. M.; Messina, C. A.; Patton, R. L.; Gajek, R. T.; Cannan, T. R.; Flanigen, E. M. Silicoaluminophosphate Molecular Sieves: Another New Class of Microporous Crystalline Inorganic Solids. J . Am. Chem. Soc. 1984, 106, 6092.

(6) Flanigen, E. M.; Lok, B. M.; Patton, R. L.; Wilson, S. T. Aluminophosphate Molecular Sieve in Periodic Table. In Proceedings of the 7th International Zeolite Conference, Tokyo, J apan, 1986; Murakami, J., Iijimi, A.; Ward, W., Eds.; Kodansha and Elsevier: Tokyo and Amsterdam, 1986; p 103.

(7) Pyke, D. R.; Whitney, P.; Houghton, H. Chemical Modification of Crystalline Microporous Aluminum Phosphate. Appl. Catal. 1985, 18, 173.

(8) Leu, L. J .; Chao, K.-J . Chemical Modification of Molecular Sieve Aluminophosphate Number 5. Proc. Natl. Sci. Counc. Repub. China, Part A 1988, 12, 91.

(9) Minchev, C.; Zubkov, S. A.; Valtchev, V.; Minkov, V.; Micheva, N.; Kanazirev, V. Nature of the Active Sites and Catalytic Activity of SAPO-5 Synthesized in the Presence of Nickel Cations. Appl. Catal. A 1994, 119, 195.

(10) Lischke, G.; Parltz, B.; Lohse, U.; Schreier, E.; Fricke, R. Acidity and Catalytic Properties of MeAPO-5 Molecular Sieves. Appl. Catal. A 1998, 166, 351.

(11) Tsoncheva, T.; Dimitrova, R.; Minchev, C. Methanol Conversion as a Test for Framework Cobalt Elucidation in CoAPSO Molecular Sieves. Appl. Catal. A 1998, 171, 241.

(12) Wan, B.-Z.; Huang, K.; Yang, T. C.; Tai, C.-Y. Characterization and Catalytic Properties of MAPO-5. J . Chin. Inst. Chem Eng. 1991, 22 (1), 17.

(13) Parrillo, D. J .; Pereira, C.; Kokotailo, G. T.; Gorte, R. J. Characterization of $\mathrm{Mg}$ and $\mathrm{Mn}$ Substitution in AIPO $4-5$. J . Catal . 1992, 138, 377

(14) Wan, B.-Z.; Huang, K. MnAPO-5 as a Catalyst for Ethane Oxydehydrogenation. Appl. Catal. 1991, 73, 113.

(15) Kao, C. Y.; Huang, K. T.; Wan, B.-Z. Ethane Oxydehydrogenation over Supported Vanadium Oxides. Ind. Eng. Chem. Res. 1994, 33, 2066

(16) Concepción, P.; López Nieto, J . M.; Pérez-Pariente, J . The Selective Oxidative Dehydrogenation of Propane on Vanadium Aluminophosphate Catalysts. Catal. Lett. 1993, 19, 333.

(17) Concepción, P.; López Nieto, J. M.; Pérez-Pariente, J. Oxidative Dehydrogenation of Ethane on a Magnesium-Vanadium Aluminophosphate (M gVAPO-5) Catalyst. Catal. Lett. 1994, 28, 9.

(18) Concepción, P.; López Nieto, J. M.; Pérez-Pariente, J Oxidative Dehydrogenation of Propane on VAPO-5, $\mathrm{V}_{2} \mathrm{O}_{5} / \mathrm{AIPO}_{4}-5$ and $\mathrm{V}_{2} \mathrm{O}_{5} / \mathrm{MgO}$ Catalysts. Nature of Selective Sites. J . Mol. Catal . A 1995, 99, 173

(19) Concepción, P.; Corma, A.; López Nieto, J . M.; PérezPariente, J. Selective Oxidation of Hydrocarbons on V-and/or CoContaining Aluminophosphate (MeAPO-5) Using Molecular Oxygen. Appl. Catal. A 1996, 143, 17

(20) Concepción, P.; López Nieto, J. M.; Mifsud, A.; PérezPariente, J . Synthesis, Characterization and Catalytic Properties of Microporous MgVAPO-5. Appl. Catal. A 1997, 151, 373.
(21) Weckhuysen, B. M.; Vannijvel, I. P.; Schoonheydt, R. A. Chemistry and Spectroscopy of Vanadium in VAPO-5 Molecular Sieves. Zeolites. 1995, 15, 482.

(22) Lin, S. S.; Weng, H. S. Liquid-Phase Oxidation of Cyclohexane Using CoAPO-5 as the Catalyst. Appl. Catal. A 1993, 105, 289.

(23) Lin, S. S.; Weng, H. S. Liquid-Phase Oxidation of Cyclohexane over CoAPO-5: Synergism Effect of Coreactant and Solvent Effect. Appl. Catal. A 1994, 118, 21.

(24) Chen, J . D.; Sheldon, R. A. Selective Oxidation of Hydrocarbons with $\mathrm{O}_{2}$ over Chromium Aluminophosphate-5 Molecular Sieve. J . Catal. 1995, 153, 1.

(25) Goldfarb, D. MAS NMR and EPR. Study of MnAIPO5. Zeolites 1989, 9, 509.

(26) Levi, Z.; Raitsimring, A. M.; Goldfarb, D. ESR and Electron Spin-Echo Studies of MnAIPO5. J . Phys. Chem. 1991, 95, 7830.

(27) Lee, C. W.; Chen, X.; Brouet, G.; Kevan, L. Comparative Spectroscopic Studies on MnSAPO-11, (L)MnH-SAPO-11, and (S)$\mathrm{MnH}-\mathrm{SAPO}-11$ Molecular Sieves (SAPO = Silicoaluminophosphate). J . Phys. Chem. 1992, 96, 3110.

(28) Brouet, G.; Chen, X.; Lee, C. W.; Kevan, L. Evaluation of $\mathrm{Mn}(\mathrm{II})$ Framework Substitution in MnAPO-11 and $\mathrm{Mn}-\mathrm{Impreg}$ nated $\mathrm{AlPO}_{4}-11$ Molecular Sieves by Electron Spin Resonance and Electron Spin-Echo Modulation Spectroscopy. J . Am. Chem. Soc. 1992, 114, 3720.

(29) Hong, S. B.; Kim, S. J .; Choi, Y.-S.; Uh, Y. S. Electron Spin Resonance Studies of $\mathrm{O}_{2}{ }^{-}$Adsorbed on Aluminophosphate $\mathrm{M}$ olecular Sieves. Stud. Surf. Sci. Catal. 1997, 105, 779.

(30) Sinha, A. K.; J acob, N. E.; Stinivas, D.; Sivasanker, S. Location of Mn in MnAPO-11: influence of synthesis from aqueous and nonaqueous media. Catal. Lett. 1999, 61, 193.

(31) Kijlstra, W. S.; Poels, E. K.; Bliek, A.; Weckhuysen, B. M.; Schoonheydt, R. A. Characterization of $\mathrm{Al}_{2} \mathrm{O}_{3}$-Supported Manganese Oxides by Electron Spin Resonance and Diffuse Reflectance Spectroscopy. J . Phys. Chem. B 1997, 101, 309.

(32) Ashtekar, S.; Chilukuri, S. V. V.; Prakash, A. M.; Chakrabarty, D. K. Small Pore Aluminum Phosphate Molecular Sieves with Chabazite Structure: Incorporation of Manganese in the Structure -34 and -44. J . Phys. Chem. 1996, 100, 3665.

(33) Kim, S. J .; Kim, M. H.; Hong, S. B.; Uh, Y. S.; Choi, Y.-S. Adsorption of Oxygen on the Paramagnetic Defect Centers in Aluminophosphate Molecular Sieves. Catal. Lett. 1997, $44(3,4)$, 165.

(34) Che, M.; Tench, A. J . Characterization and Reactivity of Molecular Oxygen Species on Oxide Surface. Adv. Catal. 1983, $32,1$.

(35) Kapteijn, F.; van Langeveld, A. D.; Moulijn, J . A.; Andreini, A.; Vuurman, M. A.; Turek, A. M.; J ehng, J .-M.; Wachs, I. E. Alumina-Supported Manganese Oxide Catalysts 1 . Characterization: Effect of Precursor and Loading. J . Catal. 1994, 150, 94.

(36) Kapteijn, F.; Singoredjo, L.; Andeini, A.; Moulijn, J. A. Activity and Selectivity of Pure Manganese Oxides in the Selective Catalytic Reduction of Nitric Oxide with Ammonia. Appl. Catal. B: Environ. 1994, 3, 173.

(37) Rajic, N.; Stojakovic, D.; Hocevar, S.; Kaucic, V. On the Possibility of Incorporating $\mathrm{Mn}(\mathrm{II})$ and $\mathrm{Cr}(\mathrm{III})$ in SAPO-34 in the Presence of I sopropylamine as a template. Zeolites 1993, 13, 384.

(38) Che, M.; Tench, A. J . Characterization and Reactivity of Mononuclear Oxygen Species on Oxide Surfaces. Adv. Catal. 1982, 31, 77.

(39) $\mathrm{Wu}, \mathrm{J} .-\mathrm{Y}$. Kinetics and Mechanism of Ethane Oxydehydrogenation over AIPO-5 and MeAPO-5. Ph. D. Dissertation, National Taiwan University, Taipei, Taiwan, 1995. Wu, J .-Y.; Wan, B.-Z. Kinetic Study of Ethane Oxydehydrogenation over AIPO-5. Ind. Eng. Chem. Res. 1993, 32, 2987.

Received for review March 3, 2000 Revised manuscript received J uly 11, 2000 Accepted September 27, 2000 